\title{
A Potential Anti-schistosomal Agent Containing 1,2,5-Oxadiazole-2-oxide and Praziquante Moieties ${ }^{1}$
}

\author{
Qinghao Wang*, Xionglu Zhang \\ College of Chemistry and Chemical Engineering, Gannan Normal University, Ganzhou 341000, \\ China
}

Keywords: Sulfone; 1,2,5-Oxadiazole; Praziquante; Anti-schistosomal Agent

Abstract: 3-Praziquantel-4-(4-chlorophenylsulfonyl)-1,2,5-oxadiazol-2-oxide was synthesized via the coupling reaction of praziquante and 1,2,5-oxadiazole in ethylene glycol, and its molecular structure was confirmed by the melting point and spectroscopic data (UV, IR, and ${ }^{1} \mathrm{H}$ NMR). Moreover, it may be a potential anti-schistosmal agent.

\section{Introduction}

3,4-Bis(phenylsulfonyl)-1,2,5-oxadiazole-2-oxide is an important class of Furoxan-based NO donors $^{[1,2]}$. It not only can regulate various physiological functions in the living organisms via the NO release, but also can make a coupling reaction with a variety of the known drugs and the activated compounds. Thus it has potential applications in new drug research ${ }^{[3,4]}$. Praziquante is a kind of new anti-schistosomal drug, and NO that released from praziquante can effectively kill schistosoma and its eggs ${ }^{[5,6]}$. The above two NO donors can make a coupling reaction in ethylene glycol and form a NO donor which can serves as a new anti-schistosomal drug ${ }^{[7,8,9]}$.

\section{Experimental}

\section{Synthesis of 2-(4-chlorophenylthio)acetic acid}

A mixture of 4-chlorothiophenol $(8.15 \mathrm{~g}, 0.055 \mathrm{~mol})$ and sodium hydroxide $(2.2 \mathrm{~g}, 0.055 \mathrm{~mol})$ was dissolved in ethanol $(110 \mathrm{~mL})$ to give a light-yellow solution, and then an aqueous solution $(200 \mathrm{~mL}) \mathrm{of}$ 2-chloroacetic acid $(5.7 \mathrm{~g}, 0.06 \mathrm{~mol})$ and sodium carbonate $(3.18 \mathrm{~g}, 0.04 \mathrm{~mol})$ was added at $25 \sim 27^{\circ} \mathrm{C}$. A large amount of white solid was generated after stirred for $3 \mathrm{~h}$ at room temperature, and the white solid was dissolved again to give a light-yellow transparent solution. After cooling to RT, the $\mathrm{pH}$ of the solution was adjusted to 2 by adding $16 \mathrm{~mol} / \mathrm{L} \mathrm{HCl}$ solution. The ethanol solvent was removed in reduced pressure, and a white precipitate was formed, filtered, and washed twice by water. Finally, a white rod-shaped crystalline product was obtained. Yield: $12.3 \mathrm{~g}, 76.3 \%$, mp: $61.2 \sim 66.0{ }^{\circ} \mathrm{C}$.

\section{Synthesis of 3,4-bis(4-chlorophenylsulfonyl)-1,2,5-oxadiazole-2-oxide}

2-(4-chlorophenylthio)acetic acid $(8.1 \mathrm{~g}, 0.04 \mathrm{~mol})$ was dissolved in glacial acetic acid $(32 \mathrm{~mL})$, and hydrogen peroxide $(30 \%, 8.1 \mathrm{~mL}, 0.08 \mathrm{~mol})$ was added in an ice-water bath to get a colorless solution for another $2 \mathrm{~h}$. Fuming nitric acid $(95 \%, 16 \mathrm{~mL}, 0.36 \mathrm{~mol})$ was then added slowly and refluxed for 0.5 h. After cooling to RT, a white needle-like crystalline precipitate was formed, filtered and dried. Yield: 3.2g, $69 \%$, mp: $181.2 \sim 183.0^{\circ} \mathrm{C}$.

Synthesis of 4-(4-chlorophenylsulfonyl)-3-(2-hydroxyethoxy)-1,2,5-oxadiazole-2-oxide

3,4-Bis(4-chlorophenylsulfonyl)-1,2,5-oxadiazole-2-oxide (2.01 g, $5 \mathrm{mmol}$ ) was dissolved in THF $(40 \mathrm{~mL})$. Ethylene glycol $(3.1 \mathrm{~g}, 50 \mathrm{mmol})$ was added and sodium hydroxide solution $(25 \%, 0.8 \mathrm{~mL})$ was then added slowly at $25 \sim 27^{\circ} \mathrm{C}$. The reaction was carried out until a lot of white solid appeared. The solvent was evaporated in reduced pressure, and the residue was dissolved in 50ml ethyl acetate, and washed with water until the solution is neutral. The product is obtained by filtration and dried. Yield: $1.28 \mathrm{~g}, 59 \%$, mp: $124.0 \sim 133.1^{\circ} \mathrm{C}$. 


\section{Synthesis of 3-praziquantel-4-(4-chlorophenylsulfonyl)-1,2,5-oxadiazol-2-oxide}

4-(4-chlorophenylsulfonyl)-3-(2-hydroxyethoxy)-1,2,5-oxadiazole-2-oxide (0.641 g, 2 mmol) was dissolved in $\mathrm{CH}_{2} \mathrm{Cl}_{2}(50 \mathrm{~mL})$, and praziquante $(0.686 \mathrm{~g}, 2.2 \mathrm{mmol})$ was added, followed by addition of fuming sulfuric acid $(98 \%, 15 \mathrm{~mL})$. Under acidic condition, even on the position of praziquante on the occurrence of benzene Fourier alkylation reaction occurred and the target product 3-praziquantel-4-(4-chlorophenylsulfonyl)-1,2,5-oxadiazol-2-oxide was afforded. Yield: 25\%, mp: $175.0 \sim 179.1^{\circ} \mathrm{C}$. Selected IR $\left(\mathrm{KBr}, \mathrm{cm}^{-1}\right): 1743\left(v_{\mathrm{C}=\mathrm{O}}\right), 1617\left(v_{\mathrm{C}=\mathrm{N}}\right), 1552\left(v_{\mathrm{C}=\mathrm{C}}\right), 1282,1238\left(v_{\mathrm{N} \rightarrow \mathrm{O}}\right)$, $1170\left(v_{\mathrm{C}-\mathrm{O}}\right), 732\left(v_{\mathrm{C}-\mathrm{Cl}}\right), 1451\left(\delta_{\mathrm{S}-\mathrm{CH} 2}\right), 1362\left(\delta_{\mathrm{S}-\mathrm{CH} 3}\right), 830\left(\delta_{\mathrm{S}-\mathrm{CH}}\right), 597\left(\delta_{\mathrm{SO} 2}\right) .1 \mathrm{H} \mathrm{NMR}\left(\mathrm{CD}_{3} \mathrm{OD}, 400\right.$ MHz): 1.72 (s, 6H, $\left.\mathrm{CH}_{3}\right), 4.50$ (t, 4H, $\left.\mathrm{CH}_{2} \mathrm{CH}_{2}\right), 5.18$ (d, 2H, OAr-3 ', 5'-H), 7.19 (d, 2H, Oar-2 ', 6'-H), 7.24 (t, 2H, SO $\left.\mathrm{SO}_{2} \mathrm{Ar}-3,5-\mathrm{H}\right), 7.35$ (t, H, SO$\left.{ }_{2} \mathrm{Ar}-4-\mathrm{H}\right), 7.60$ (d, 2H, $\left.\mathrm{SO}_{2} \mathrm{Ar}-2,6-\mathrm{H}\right)$.

\section{Physical Measurements}

${ }^{1} \mathrm{H}$ NMR spectrum was recorded on Bruker Avance III (400 MHz) spectrometer with $\mathrm{SiMe}_{4}$ as the internal reference in $\mathrm{CD}_{3} \mathrm{OD}$. UV absorption spectrum in $\mathrm{CH}_{2} \mathrm{Cl}_{2}$ was measured on a Shimadzu cintra10 spectrometer. The melting points was performed on a WHF203B micro melting point apparatus. Fourier transform infrared (FT-IR) spectra was collected on a AVATAR 360 FT-IR spectrometer (Australia GBC Scientific Instrument) using KBr pellet.

\section{Results and Discussion}

The target product 3-praziquantel-4-(4-chlorophenylsulfonyl)-1,2,5-oxadiazol-2-oxide has been successfully synthesized (Scheme 1). It is a white flocky crystalline solid, and it is soluble in ethyl acetate and sparingly soluble in methanol. In its UV spectrum (Figure 1), there are two main absorption bands maximized at $224 \mathrm{~nm}$ and $252 \mathrm{~nm}$, respectively. In the infrared spectrum, its characteristic $v(\mathrm{C}=\mathrm{O})$ peak appears at $1745 \mathrm{~cm}^{-1}$. All the proton signals can be observed in its ${ }^{1} \mathrm{H}$ NMR spectrum (Figure 2).

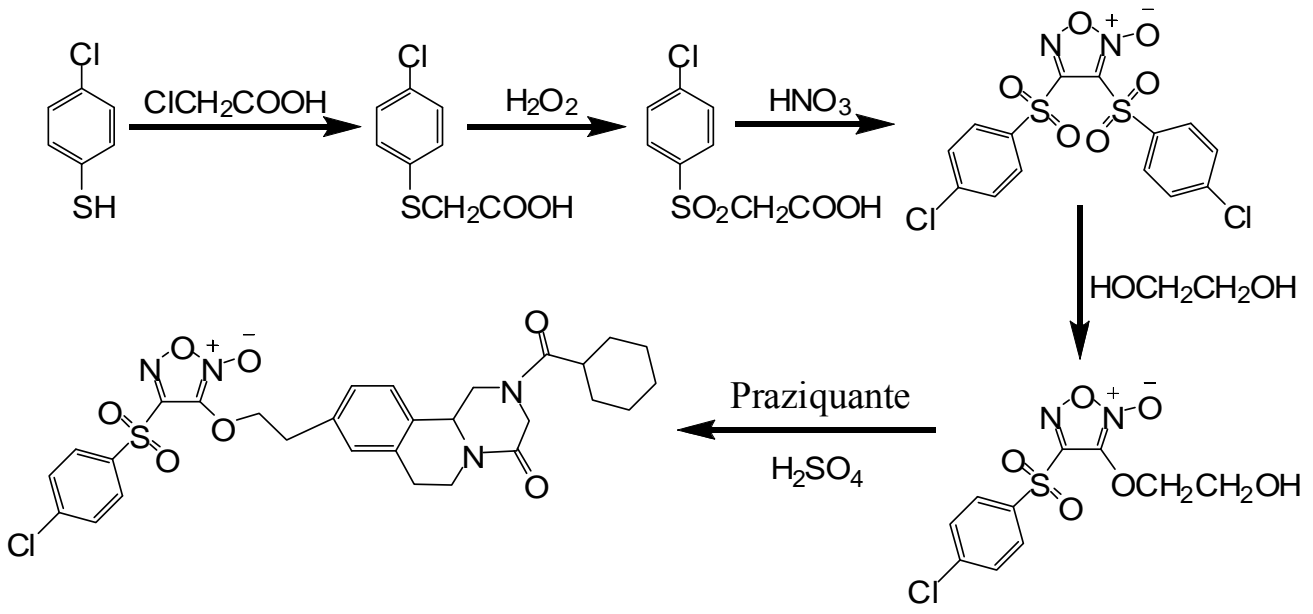

Scheme 1. Synthetic route of the target compound 


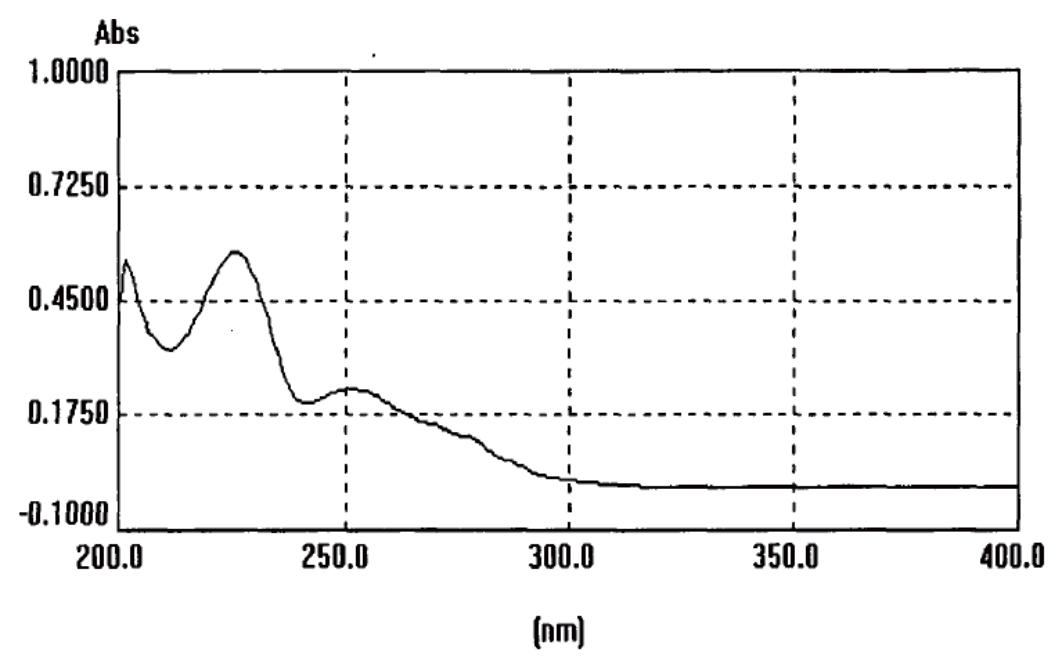

Figure 1. UV spectrum of the target compound

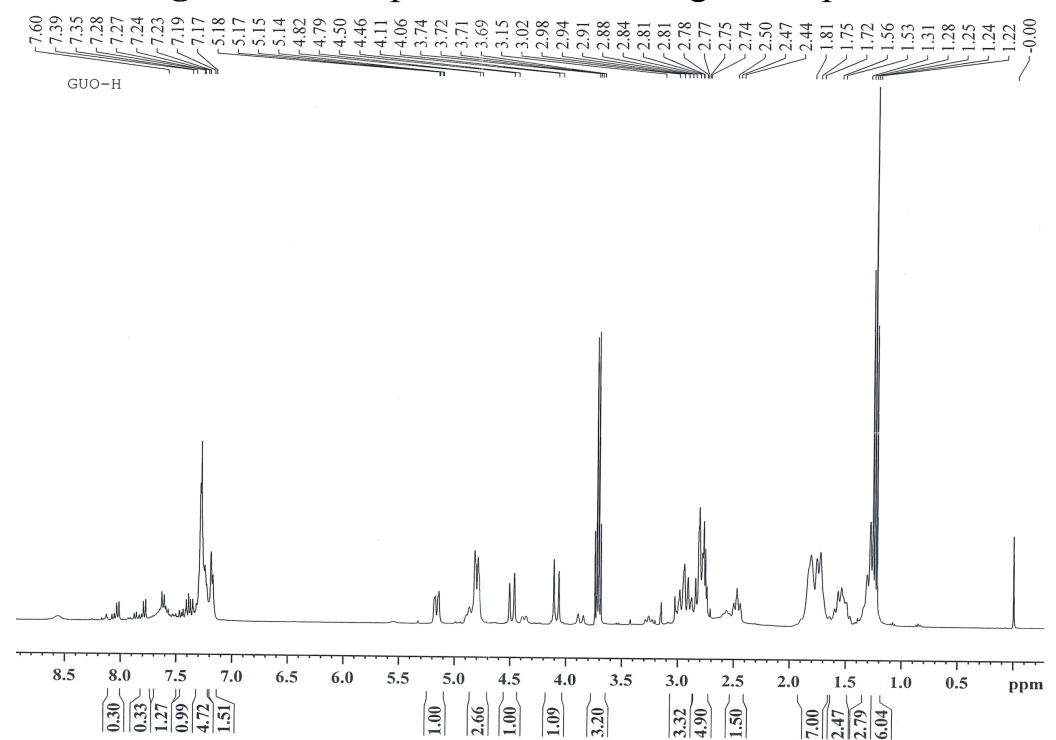

Figure 2. ${ }^{1} \mathrm{H}$ NMR spectrum of the target compound in $\mathrm{CD}_{3} \mathrm{OD}$

\section{Conclusion}

3-Praziquantel-4-(4-chlorophenylsulfonyl)-1,2,5-oxadiazol-2-oxide has been successfully synthesized by the coupling reaction between 3,4-bis(phenylsulfonyl)-1,2,5-oxadiazole-2-oxide and praziquante in ethylene glycol. Its molecular structure has been characterized by the melting point and spectroscopic data (UV, IR, and ${ }^{1} \mathrm{H}$ NMR), and it may be a potential anti-schistosmal agent.

\section{References}

[1] S. Barta, T. Rriinivasan, S. Rastogi, B. Kundun, A. Parta, A.P. Bharduri, M. Dxit.Bioorg. Med. Chem. Lett. 12 (2002) 1905-1910.

[2] P. Viachos, B. Mansoor, M.P.O. Alfred, M. Nell, S.M. Kelly. Chem. Commun. (2005) 2921-2926.

[3] A. Nortcliffe, A.G. Ekstrom, J.R. Black, J.A. Ross, F.K. Habib, N.P. Botting, D. O’Hagan. Bioorg. Med. Chem. 22 (2014) 756-761.

[4] R. Shan, C. Velzquez, E.E Knauz. J. Med. Chem. 47 (2003) 254-261.

[5] E. Gumpricht, R. Dahl, M.W. Devereaux, R.J. Sokol. J. Biol. Chem. 280 (2005) 10556-10561.

[6] R.W. Li, Y.H. Zhang, H. Ji, X.L. Yu, S.X. Peng. Acta Pharm. Sin. 36 (2001) 821-826.

[7] D.R. Seimens, J. Heaton, M. Adams, C. Graham. Nitric Oxide. 17 (2007) 515-521.

[8] M. Deshmukh, P. Chao, H.L. Kutscher, D. Gao, P.J. Sinko. J. Med. Chem. 53 (2010) 1038-1043. 
[9] Y. Ling, X. Ye, H. Ji, Y. Zhang, Y. Lai, S. Peng, J. Tian. Bioorg. Med. Chem. 18 (2010) 3448-3453. 